\title{
Respon Remaja Tentang Kasus Cyberbullying Sulli Dan Goo Hara
}

\author{
Dwi Putri Robiatul Adawiyah \\ Magister Komunikasi dan Penyiaran Islam, UIN Sunan Ampel Surabaya, Indonesia. \\ Email:putrirad@gmail.com \\ (corresponding author)
}

Muhammad Munir

Magister Komunikasi dan Penyiaran Islam, UIN Sunan Ampel Surabaya, Indonesia. Email:muniralafasy39@gmail.com

\section{Article Info}

\section{Article History}

Received 23 Nov 2019 Revised 30 Oct 2020

Accepted 9 Nov 2020

\begin{abstract}
Cyberbullying is the act of hurting, embarrassing, or distressing people because all the disgrace is publicized on social media. The victim becomes depressed and commits dangerous things such as suicide. This study aims to explain adolescent responses about Sulli and Goo Hara's cyberbullying that cause death. The author applied descriptive qualitative methods. The results revealed the lack of netizen knowledge and consequences on Sulli and Goo Hara's mental health made them not careful in commenting on social media. Therefore, it is important for netizens to be careful about everything that will be posted on social media in order not to get meanly impact to others.
\end{abstract}

Keywords: response, youth, cyberbullying, fans

\begin{abstract}
Abstrak: Cyberbullying adalah tindakan menyakiti, membuat malu, atau membuat orang tertekan karena semua aibnya dipublikasikan di media sosial. Dampaknya bagi korban, dapat mengalami depresi yang mendorong korban melakukan sesuatu yang membahayakan diri sendiri seperti bunuh diri. Penelitian ini ingin mengetahui berbagai respon remaja tentang kasus cyberbullying Sulli dan Goo Hara yang mengakibatkan kematian. Metode penelitian menggunakan kualitatifdeskriptif. Hasil penelitian mengungkapkan bahwa kurangnya pemahaman netizen mengenai akibat cyberbullying terhadap mental health Sulli dan Goo Hara membuatnya tidak berhati-hati dalam berkomentar di media sosial. Oleh karena itu, penting bagi netizen berhati-hati terhadap segala sesuatu yang akan diposting di media sosial agar tidak berdampak buruk bagi orang lain.
\end{abstract}

Kata kunci: respon, remaja, cyberbullying, fans 


\section{PENDAHULUAN}

Bullying dalam makna harfiah berarti menggertak dan mengganggu orang yang lebih lemah (Siswati \& Widayanti, 2011). Bullying seperti ibarat seseorang tidak suka minum kopi pahit, tapi dipaksa untuk meminumnya maka seperti itulah rasanya di-bully. Oleh karena itu, menjadi bullying victim (korban bullying) tidaklah menyenangkan. Ini karena jika tingkatannya sudah parah, dapat menyulut bunuh diri ataupun menghancurkan kehidupan korban (Elvigro, 2014). Menurut Siswati \& Widayanti (2011) "Bullying is the willful, conscious desire to hurt another and put him or her under stress" (Bullying adalah tindakan yang buruk, dimana dia sadar untuk menyakiti seseorang dan menempatkan dia di bawah tekanan).

Tindakan bullying bisa dilakukan dengan berbagai cara. Menurut Tim Yayasan Sehati Jiwa Amini (2008) bullying terbagi di dalam dua bentuk, yaitu secara fisik ataupun non-fisik. Bullying secara fisik dapat dilakukan dengan memukul, menendang, meninju, menggigit, menarik, menjambak rambut, mencakar, meludahi ataupun merusak barang-barang milik korban. Oleh karena itu, bullying secara fisik akan mudah diidentifikasi. Sementara itu, bullying secara non-fisik terbagi menjadi dua, yaitu secara verbal maupun non-verbal.

Bullying secara verbal dilakukan dengan mengancam, memeras, berkatakata kasar, dan memanggil dengan maksud untuk mengejek, berkata-kata dengan menekan, menggosip ataupun menyebarluaskan aib tentang si korban. Sebaliknya, bullying non-verbal bisa dilakukan secara langsung maupun tidak langsung. Secara langsung, bentuknya hampir sama dengan tindakan secara fisik, tapi lebih kepada tindakan mengancam dengan tatapan mata, meninju-ninju atau menghantam benda-benda agar si korban takut. Bullying non-verbal secara tidak langsung seperti mengucilkan seseorang, melakukan penghasutan, berlaku curang atau bahkan melakukan tindakan menyebarkan berita bohong atau manipulasi yang berkaitan dengan diri korban (Priyanta, 2010).

Kehadiran media sosial telah mengubah sedemikian rupa bentukbentuk bullying. Jika dahulu bullying dilakukan secara langsung (dalam arti tatap muka), tetapi saat ini dapat dilakukan di dunia cyber (tanpa tatap muka) (Kowalski et al., 2008; Parsons, 2005). Bullying jenis ini memanfaatkan perkembangan teknologi informasi dan komunikasi seperti fasilitas internet, handphone, komputer, kamera, perekam video/audio. Dengan memanfaatkan teknologi yang ada, pelaku dapat mengirimkan pesan dalam bentuk teks, gambar atau video yang dapat bersifat mengancam, menyebarkan rumor, dan terror. Hal ini tentunya tidak hanya dapat memalukan korban, tetapi juga dapat menyakiti korban karena aibnya menjadi konsumsi publik dan susah untuk menghapus sesuatu yang telah diunggah tersebut (Kowalski et al., 2008). Dalam kaitan ini, perilaku yang disengaja, sering diulang-ulang, dan bermusuhan dimaksudkan untuk menyakiti korban menggunakan media teknologi informasi dan komunikasi, paling sering dilakukan melalui ponsel dan internet (Kowalski et al., 2008).

Bullying baik ringan ataupun berat tetap dapat menyebabkan korban tertekan (Elvigro, 2014). Situasinya akan menjadi semakin parah jika kegiatan tersebut dilakukan secara berulang-ulang dengan tempat yang berbeda. Pada umumnya, bullying kerap terjadi di area sekolah, ruang kelas, toilet, halaman atau ruang loker sekolah, kantin sekolah, bahkan bisa 
juga terjadi didekat rumah (Astuti, 2008). Levianti (2008) mengungkapkan hasil penelitiannya di Jerman bahwa 60,1\% bullying terjadi di sekolah, 17,3\% terjadi saat perjalanan pulang sekolah, dan 9,2 \% terjadi di dalam kelas atau toilet. Dari sini, dapat disimpulkan bahwa mayoritas kisah bullying berlatarkan sekolahan.

Hasil studi yang dilakukan oleh National Youth Violence Prevention Resource Center pada tahun 2003 menunjukkan bahwa bullying dapat mengakibatkan seseorang remaja merasa ketakutan dan cemas, dapat mempengaruhi konsentrasi belajar di sekolah dan mengakibatkan seseorang menghindari sekolah (Andriani et al., 2011). Bullying berkelanjutan secara terusmenerus dapat mempengaruhi self-esteem (kepercayaan diri) si korban, mengakibatkan isolasi terhadap dunia sosial, memunculkan perilaku withdrawal (menarik diri dari lingkungan), gampang setres dan depresi, serta adanya rasa tidak aman. Akibat terburuk dapat menyebabkan seseorang bunuh diri apabila sudah tidak kuat dengan situasi/tekanan tersebut (Murphy, 2009).

\section{Cyberbullying terjadi dalam}

konteks sosial dan bertujuan untuk mempermalukan seseorang di depan orang lain. Mengacu pada definisi integratif, cyberbullying adalah "segala perilaku yang dilakukan melalui media elektronik atau digital oleh individu atau kelompok yang berulang kali, mengkomunikasikan pesanpesan yang bermusuhan atau agresif yang dimaksudkan untuk menimbulkan kerugian atau ketidaknyamanan pada orang lain (Breguet, 2007).

Perbedaan antara cyberbullying
langsung dan tidak langsung.
Cyberbullying langsung mencakup
komunikasi negatif langsung antara doer
(Pelaku) dan victim (korban), sedangkan
dalam cyberbullying tidak langsung,
bullying tidak mengarah komunikasi

konten negatif langsung ke victim, tetapi ke publik atau semi- khalayak publik melalui internet atau ponsel (Elvigro, 2014). Dalam kasus cyberbullying tidak langsung, audiens mewakili prasyarat yang diperlukan untuk cyberbullying dan bagaimana orang-orang ini (atau pengamat) bereaksi terhadap insiden tersebut dapat mempengaruhi proses lebih lanjut dari cyberbullying secara signifikan (Kowalski et al., 2008). Kelompok yang tergolong dalam orang ini mungkin berperilaku pasif, tetapi secara aktif dapat mendukung victim (korban) atau memperkuat doer (pelaku). Jenis pola perilaku yang seperti inilah yang disebut ini sebagai peran cyberbullying, yang memiliki tujuan untuk menganalisis secara empiris dalam penelitian ini. Maka, konseptualisasi peran cyberbullying sebagian besar didasarkan pada pertimbangan teoritis atau pendekatan yang berpusat pada variabel dengan mengelompokkan pernyataan yang diberikan ke dalam skala, tetapi penelitian ini membedakan beberapa peran cyberbullying berdasarkan pola jawaban responden. Pendekatan yang berpusat pada orang seperti itu membantu mengidentifikasi peran-peran penindasan cyber yang khas yang terjadi dalam kehidupan nyata remaja (Rigby, 1996).

\section{Penelitian mengenai cyberbullying} belum terlalu banyak diteliti sehingga menjadikannya menarik untuk dibahas dan dikaji lebih dalam. Berbeda dengan bullying yang dilakukan secara offline (langsung) yang sudah banyak dilakukan, cyberbullying sedikit sekali ditemukan. Namun, dalam banyak penelitian, peran partisipan dalam penindasan di cyber dikonseptualisasikan secara berbeda dari penindasan offline. Seseorang sering dikategorikan menjadi pelaku, korban, dan siswa yang tidak terlibat (Elvigro, 2014). Pertanyaan tambahan dimasukkan dalam studi untuk mengidentifikasi para doer (pelaku) bullying. Elvigro (2014) menulis, 
"[memperhatikan] situasi sosial yang terjadi di dunia cyber antara doer (pelaku) dan victim (korban), dan mungkin orang lain yang memperhatikan kejadian ini”. Ini kemudian disebut bystanders atau saksi. Meskipun korelasi perilaku telah dianalisis dan dibandingkan untuk kelompok ini, peran ini belum diekstraksi secara empiris sejauh ini, yaitu menggunakan pendekatan berbasis data berdasarkan pola jawaban. Tujuan penelitian ini pada dasarnya untuk mengetahui respon remaja tentang kasus cyberbullying Sulli dan Goo Hara yang mengakibatkan kematian.

Di Indonesia, tayangan televisi merupakan salah satu penyebab kasus bullying yang terjadi, seperti yang dilansir dalam suara.com pada 11 April 2019 yang berjudul "Kasus Kekerasan Terhadap Audrey, Psikolog Ungkap 2 Pemicu Kekerasan". Artikel tersebut menyebutkan bahwa salah satu penyebab perilaku bullying, yakni faktor melihat tayangan kekerasan di televisi, bahkan 60-70\% tayangan dapat mempengaruhi psikologis, kejiwaan cara berpikir, emosi serta perilaku seseorang. Pertelevisian di Indonesia banyak menayangkan sinteron yang mengangkat kisah tentang kebrutalan, perkelahian yang secara tidak langsung memberikan dampak negatif pada kognitif/berpikir dan fungsi psikologis seseorang (Widiastuti, 2019).

Selain itu, kasus bullying banyak terjadi di media sosial seperti Facebook, Twitter, dan Blog (Hidajat et al., 2015). Seseorang yang memberikan komentar atau mention negatif terhadap postingan yang diunggah seseorang juga termasuk bentuk bullying verbal secara tidak langsung. Dampak luar biasa akibat bullying seperti dirujuk penelitian ini adalah kasus Goo Hara artis Korea Selatan yang bunuh diri, ditemukan meninggal di rumahnya di kawasan Gangnam, Seoul, pada hari minggu 24 November 2019. Sebelum meninggal, Goo Hara kerap menerima komentar-komentar negatif, baik karena masalah kekerasan yang dilakukan mantan pacarnya ataupun operasi plastik (Rosewarne, 2016).

Goo Hara melalui siaran langsung di Instagram pada 15 Oktober 2019 mengatakan, ia akan melanjutkan sisa hidupnya demi Sulli. Goo Hara juga menderita depresi, dan pernah selamat dari percobaan bunuh diri pada Mei 2019. Sebelumnya, Goo Hara terlilit masalah dengan mantan kekasihnya, Choi Jong Bum yang mengancam akan menyebarkan video intim yang terjadi pada Hara. Akibat kasus ini, Hara justru diserang komentar negatif dan jahat atau cyberbullying di media sosial. Kematian Goo Hara terjadi kurang dari dua bulan dari kepergian bintang K-pop lainnya Sulli yang nekat mengakhiri hidupnya karena cyberbullying yang dialaminya.

Cyberbullying sulit dihindari terlebih lagi dengan berkembangnya teknologi yang semakin canggih sehingga memudahkan mengakses segala sesuatu yang dapat berpeluang juga pada semakin maraknya fenomena cyberbullying. Penelitian (Uswatun et al., 2016) mengungkapkan krisis kesantunan dan etika di media sosial. Penelitian tersebut menjelaskan bahwa pengguna media sosial kurang memperhatikan etika berbicara dalam media sosial yang dapat memunculkan cyberbullying. Pada dasarnya, perilaku cyberbullying dilakukan karena adanya perilaku yang tidak sesuai dengan norma yang ada dalam masyarakat. Oleh karena itu, ketika menjadi korban cyberbullying hendaknya mencari seseorang yang dapat membantu menyelesaikan permasalahan tersebut. Namun, kebanyakan anak-anak ketika menjadi korban cyberbullying tidak berani mengungkapkannya pada orang dewasa. Ini dapat berakibat negatif terhadap kondisi psikologisnya. Sebagaimana diungkap oleh (Vaillancourt et al., 2017) 
bullying dan cyberbullying biasanya tidak dilaporkan kepada orang dewasa karena anak-anak khawatir tentang konsekuensi dari menceritakan pada orang tua atau guru. Meski banyak menjadi korban, anakanak dan remaja tidak merasa nyaman memberi tahu guru atau bahkan orang tua sendiri tentang rasa sakit yang dialami.

$\begin{array}{rcr}\text { Jenis } & \text { kelamin juga dapat } \\ \text { berpengaruh } & \text { terhadap perilaku }\end{array}$
cyberbullying. Sebagaimana diungkap oleh (Barlett \& Coyne, 2014) remaja lakilaki lebih mungkin untuk berpartisipasi dalam keseluruhan penindasan dan untuk menggunakan bentuk-bentuk langsung dari intimidasi tradisional, seperti fisik dan verbal, sedangkan perempuan lebih suka menggunakan bentuk-bentuk intimidasi tidak langsung dan berhubungan. Penelitian yang dilakukan (Bendre et al., 2020) mengungkapkan bahwa menjamurnya Web 4.0, intimidasi cyber menjadi isu yang penting. Sejumlah pengalaman intimidasi cyber yang mengancam jiwa telah dilaporkan secara internasional sehingga menarik perhatian pada dampak negatifnya. Deteksi intimidasi daring dan tindakan pencegahan selanjutnya adalah tindakan utama untuk memeranginya. Ada dua fase yang digunakan. Fase pertama bertujuan untuk mendeteksi pesan berbahaya secara akurat. Dalam penelitian ini, Nihar dkk mencoba menyajikan cara pemilihan fitur, yaitu fitur umum dan sentimen. Fase selanjutnya bertujuan untuk menganalisis jejaring sosial untuk mengidentifikasi pemangsa dan korban melalui mereka interaksi pengguna, dan sajikan hasilnya dalam model grafik. Algoritma peringkat digunakan untuk mendeteksi predator dan korban yang berpengaruh. Pendekatan yang diusulkan untuk anti-cyber bullying menggunakan matriks pendeteksian cyberbullying terkomputasi dan representasi grafis terkait dari hasilnya adalah unik.
Dalam penelitian ini, fokus yang akan dikaji adalah mengenai tanggapan remaja yang dianggap peneliti mempunyai pandangan mendalam dan aktual dalam menanggapi kasus cyberbullying yang terjadi pada artis Korea Sulli dan Goo Hara. Untuk itu, penelitian ini berusaha menganalisis respons remaja tentang kasus cyberbullying yang mengakibatkan kematian. Dari analisis tersebut, diharapkan dapat mengungkapkan respon remaja tentang kasus cyberbullying yang mengakibatkan kematian dua artis, yakni Sulli dan Goo Hara.

\section{METODE}

Penelitian ini menggunakan metode penelitian kualitatif dengan pendekatan deskriptif. Teknik pengumpulan data dengan wawancara, observasi dan dokumentasi. Pra riset dilakukan selama setengah bulan dan pengumpulan data penelitian menghabiskan waktu kurang lebih satu bulan. Pemilihan informan dilakukan dengan Purposive sampling. Teknik ini memungkinkan peneliti untuk mengambil informan berdasarkan kriteria tertentu, misalnya, orang tersebut yang dianggap tahu tentang apa diharapkan sehingga akan memudahkan peneliti menjelajahi obyek atau situasi yang diteliti. Dengan kata lain, pengambilan sampel diambil berdasarkan kebutuhan penelitian.

Informan penelitian ini adalah remaja yang terdiri dari 15 orang laki-laki dan 15 orang perempuan. Usia informan berkisar antara 17-21 tahun dan bertempat tinggal di daerah Surabaya. Peneliti melakukan wawancara by phone terhadap orang-orang yang menjadi penggemar Sulli dan Goo Hara sebanyak 13 orang, pengikut akun instagram @jelly_killi dan @koohara sebanyak 10 orang, pengguna media sosial Instagram sebanyak 7 orang. Selain itu, data juga didukung dengan data yang ada pada akun instagram @jelly_killi 
dan@koohara. Penelitian dilakukan terhitung sejak 25 November hingga 17 Desember 2019.

\section{HASIL DAN PEMBAHASAN}

Berdasarkan data-data dari hasil wawancara dan observasi lapangan, penelitian ini memberikan gambaran tentang tanggapan remaja terhadap kasus cyberbullying di Instagram dan cara mencegah perilaku cyberbullying.

Penggemar Sulli dan Goo Hara adalah remaja berusia 17-21 tahun. Secara spesifik, tidak ada yang membedakan penampilan penggemar Sulli dan Goo Hara. Kesamaannya terletak pada ketertarikannya hanya pada kedua artis ini yang merupakan mantan personel Girl Band $\mathrm{F}(\mathrm{x})$ dan Kara. Kesamaan lainnya terletak pada ketika informan berkumpul dengan temannya akan bercerita mengenai idolanya. Mereka saling berbagi informasi dan saling mendukung satu dengan lainnya. Ketika idolanya di-bully di Instagram karena mengunggah sesuatu yang menurut netizen salah, misalnya, penggemar ini akan berdiri di depan untuk membela idolanya. Mereka akan memberikan semangat dan motivasi agar tidak terpengaruh oleh perkataan netizen.

Dalam penelitian ini, informan menyukai Sulli dan Goo hara karena menganggapnya menarik dan unik. Dalam pandangan para fans ini, Sulli dan Goo Hara dinilai cantik, jago acting, dan suaranya yang indah. Salah satu informan ada yang sudah mulai menjadi penggemar semenjak 2017 melalui berbagai macam informasi yang ada di media massa dan berlanjut hingga mengikuti kehidupan sang idola dari berbagai platform media sosial yang digunakan. Sulli dan Goo Hara sebelumnya termasuk pengguna aktif Instagram, dan seringkali menyebarkanberbagai foto ataupun video live streaming. Banyak yang menyukai maupun mencibir foto-foto mupun video yang dibagikan tersebut. Meskipun demikian, ini tak menyurutkan fans untuk tetap menyukai idolanya.

Penggemar yang tergabung dalam berbagai komunitas (fandom) akan cenderung memiliki pengetahuan lebih banyak dibandingkan dengan remaja yang tidak tergabung dalam komunitas. Mereka biasanya juga mengoleksi bermacam barang dan aksesoris. Beberapa informan mengaku bahwa para remaja mengoleksi poster, lagu dan juga CD original dari Sulli dan Goo Hara. Beberapa informan lainnya mengakui mengoleksi baju, topi yang dapat mengidentifikasi sebagai penggemar Sulli dan Goo Hara. Dari semua informan, ditemukan informasi bahwa semua informan mengoleksi puluhan film dan koleksi mp3 maupun mp4 yang diperolehnya dari hasil mengunduh melalui internet. Informan dan bahkan remaja sebayanya menggemari beberapa koleksi film-film maupun musik terpopuler di Korea.

\section{Tanggapan Atas Bullying Sulli dan Goo Hara}

Dari beberapa tanggapan remaja, banyak hal yang menyebabkan seseorang depresi dan menyebabkan kematian. Salah satunya adalah komentar negatif pada Sulli dan Goo Hara sehingga mengakibatkan keduanya bunuh diri dan berujung pada kematian. Uraian berikut akan menunjukkan beberapa tanggapan yang telah ditelaah melalui wawancara dengan fans dan pengguna media sosial.

\section{Tanggapan Fans}

Seorang penggemar tentunya akan selalu mendukung idolanya karena adanya motivasi untuk membuat idolanya bahagia agar dapat terus berkarya dan tidak mempedulikan berbagai komentar negatif 
dari netizen. Oleh karena itu, ketika mereka mendengar kabar kematian artis idolanya membuat beberapa fans bersedih. Oleh karena itu, mereka cenderung menentang bullying, dan sekaligus empati terhadap Sulli dan Goo Hara. Tanggapan mereka atas bullying Sulli dan Goo Hara juga cenderung emosional.

"sangat memilukan, cyber bullying adalah kejahatan. Kita harusnya lebih bisa memanusiakan manusia, tidak harus semudah itu membully/judge ketika sesesorang melakukan kesalahan. Mental health bukan suatu candaan, depresi bukan hal yang sepele, dan menurut saya sulli dan goo hara bukan meninggal karena bunuh diri, mereka meninggal karena dibunuh kejamnya netizen (melalui) cyberbullying." (Informan I: IN).

Hal serupa juga diungkapkan oleh AD yang mengatakan bahwa cyberbullying memiliki dampak buruk terhadap psikis seseorang yang bisa menyebabkannya bunuh diri.

"Menurut pendapat saya, cyberbullying adalah suatu perbuatan menghina, mengejek, atau semacam ujaran kebencian (hate speech). Berdasarkan informasi yang saya ketahui, cyberbullying yang terjadi pada Sulli dan Goo Hara menyebabkan kedua aktris tersebut depresi hingga akhirnya meninggal karena bunuh diri. Kejadian tersebut sangat miris. Saya yakin pasti terlalu banyak tekanan yang dirasakan oleh kedua aktris tersebut hingga menyebabkan stress, depresi yang berkepanjangan lalu akhirnya karena tidak kuat lagi menahan beban dan cobaan yangg menimpa dirinya akhirnya dia memutuskan untuk megakhiri hidupnya dengan cara bunuh diri." (Informan II : AD).

Memahami mental health dan depresi yang diidap oleh Sulli dan Goo Hara tentunya sangat penting. Sulli dan Goo Hara merupakan artis yang mendapatkan banyak komentar negatif dari netizen khususnya knetz (Korean netizen). Bunuh diri yang dilakukan oleh Sully dan Goo Hara disebabkan oleh ketidakmampuannya untuk menghindari pikiran-pikiran negatif akibat bully-an di media sosial yang dialaminya (cyberbullying).

Beberapa informan lainnya berpendapat bahwa setiap orang punya kekuatan mental. Terkadang, ada juga artis yang tidak mempermasalahkan respon dari netizen, tidak peduli ataupun biasabiasa saja ketika menjadi korban bullying. Ada artis yang beranggapan bahwa menjauhi media sosial merupakan cara yang terbaik. Ada yang tidak peduli terhadap komentar orang-orang yang tidak dikenal. Namun, ada juga yang mengalihkan semua hal-hal perundungan terhadap hal-hal yang positif, seperti selalu berfikir positif, memotivasi diri untuk selalu melakukan kebaikan, menghindari hal-hal yang berbau bully, lebih mengenali diri sendiri. Sebaliknya, berbeda halnya dengan Sully dan Goo Hara yang tidak bisa mengabaikan pikiran-pikiran negatif netizen.

\section{Tanggapan Followers}

Tanggapan kedua berasal dari informan yang mengikuti Instagram @Jelly_Jilli dan @Koohara_. Seorang pengikut Instagram bermakna bahwa orang ini menyukai beberapa unggahan yang dibagikan oleh Sulli dan Goo Hara. Tanggapan informan pada kelompok ini 
uga menaruh simpati pada Sulli dan Goo Hara, tapi tidak seemosional kelompok informan pertama.

"Sangat disayangkan, tindakan bully yang dilakukan masyarakat Korea memang seringkali terjadi, dan dampaknya besar hingga menyebabkan orang melakukan upaya bunuh diri, dan kejadian semacam Sulli, Goo Hara juga bukan pertama kalinya terjadi, menurut saya mungkin karena kesadaran tentang tindakan anti bullying dan pengetahuan kesehatan jiwa di sana juga masih rendah." (Informan III : FR)

Pernyataan serupa diungkapkan oleh GA yang bahkan menyebut pelaku cyberbullying sebagai kriminal.

"saya tidak setuju tentang cyberbullying yang dilakukan netizen kepada Sulli dan Goo Hara karena netizen melakukan itu sama dengan melukai psikisnya. Jika seseorang menyakiti psikisnya, maka ia dapat dikatakan sebagai pelaku kriminal.” (Informan IV : GA).

\section{Kurangnya kesadaran disertai pemahaman mengenai dampak} cyberbullying menyebabkan kejadian yang sama berulang-ulang. Hal itu merupakan budaya buruk Korea Selatan, dimana setiap orang berlomba-lomba saling mengalahkan, untuk menjadi yang terbaik diantara yang lain (Rastati, 2020). Apapun dilakukan demi mencapai sesuatu, termasuk belajar sampai malam, atau operasi plastik atau bisa disebut budaya kompetitif yang berlebihan (Watkins, 2018). Budaya ini dibawa dalam dunia maya.
Sebenarnya, cyberbullying terjadi di segala penjuru dunia maya. Namun, di Korea Selatan, lebih parah karena sistem perlombaan hidup tadi (Rastati, 2020) sehingga sedikit saja kejelekan terungkap akan dijadikan ajang kepuasan bersama oleh netizen. Dalam kasus ini, ketika kejelekan Sulli dan Goo Hara muncul maka berarti berhasil mengalahkan kedua artis tersebut. Dalam posisi lain, karena budaya yang sangat kompetitif, penggemar Sulli dan Goo Hara telah memilih keduanya untuk menjadi idola karena dianggap sebagai artis terbaik di antara artis lain.

\section{Tanggapan Pengguna Media Sosial Secara Umum}

Tanggapan ketiga berasal dari pengguna media sosial (Instagram) yang berposisi "netral". Ini dipahami sebagai tidak membenci ataupun menyukai artis Sulli dan Goo Hara. Tanggapan kelompok ini cenderung normatif, dan bahkan cenderung kritis terhadap fans. Pada bagian lain, mereka bahkan menyalahkan idola yang banyak mengunggah konten di media sosial sehingga memicu tanggapan negatif di media sosial. Dengan kata lain, tanggapan negatif di media sosial dirangsang oleh unggahan artis tersebut, dan bukan pada pengguna media sosial itu sendiri. 
Terus kena bully depresi??? Itu mah salah dianya sendiri yang buat. Makanya, tanamlah kebaikan pasti hasil nya baik.. Dan jgn lupa yang paling penting adalah etika.. Etika penting harus dijaga juga.. Dlm ber sosial media juga ada etikanya" (Informan III: FT)

Hal senada juga diungkapkan oleh HA bahwa seseorang harus bijak dalam menggunakan media sosial. Ini karena segala sesuatu yang terjadi pada diri kita sebagai akibat dari apa yang telah kita perbuat.

"Berani menggunakan, berani
menanggung resiko, berani
menjadi org terkenal/ public
figure, maka berani menerima
konsekuensinya dri dampak
bermedia sosial trsebut."
(Informan VI: HA)

Dua kutipan informan pengguna media sosial, tampak bahwa mereka meletakkan bullying sebagai resiko. Informan pada kelompok ketiga ini cenderung ambigu. Pada satu sisi, mereka menganggap bahwa etika media sosial penting, tapi di sisi lain meletakkan kasus bullying sebagai sebuah konsekuensi ketika seseorang menggunggah konten di media sosial. Mereka tidak menyalahkan netizen karena perilakunya yang suka mem-bully tersebut.

\section{Mencegah Bullying di Media Sosial}

Kasus bullying pada Sulli dan Goo Hara tentunya memiliki beberapa faktor, baik internal dari dirinya dan orang lain. Dalam kajian sosiologi komunikasi, golongan masyarakat saat ini dibagi menjadi dua, yaitu masyarakat nyata dan masyarakat maya (Bungin, 2011). Masyarakat nyata adalah masyarakat yang membangun sebuah interaksi secara langsung, sedangkan masyarakat daring adalah masyarakat yang melalukan aktivitas sosial di dunia maya.

Kemajuan teknologi memberikan peluang bagi masyarakat nyata untuk melakukan sebuah aktivitas daring. Aktivitas daring tersebut memberikan manfaat, sekaligus memberikan masalah. Salah satunya ialah adanya cyberbullying yang dilakukan terhadap artis dan public figure (Bungin, 2011).

Sulli dan Goo Hara menderita depresi yang disebabkan cyberbullying di Instagram. Hal tersebut terjadi karena hujatan dari para netizen yang dilontarkan pada cara berpakaian dan hubungan asmaranya. Dalam kejadian tersebut, Sulli dan Goo Hara terus terang menceritakan di Instagram@Jelly_Jilli dan @Koohara_ tentang haters yang merundungnya hingga membuatnya depresi.

Masalah yang diderita Sulli dan Goo Hara memberikan wawasan pada pengguna media sosial bahwa media sosial memberikan pengaruh pada kita untuk melakukan kejahatan kepada orang lain. Unggahan yang membuat viral jagat raya di Instagram memberikan peluang pada perundungan yang diterima oleh artis K-Pop. Dalam beberapa dekade belakangan, siksaan mental terjadi dari para haters yang melakukan perundungan (Kim, 2019).

Tanggapan informan dalam usaha mencegah perundungan juga beragam. Berbagai tanggapan mengenai kasus bullying terhadap Sulli dan Goo Hara dapat dibedakan berdasarkan tingkatan minatnya terhadap Sulli dan Goo Hara maka tanggapan terhadap pencegahan perundungan di media sosial juga beragam, antara lain : 
1. Pentingnya menjaga etika dalam berbicara, baik itu di dalam kehidupan social maupun di media sosial.

2. Hendaknya memilih konten yang akan diposting karena tidak semua orang di media social akan beranggapan positif.

3. Tidak memposting kehidupan pribadi secara berlebihan

4. Selektif dalam berteman. Memilih teman baik itu di kehidupan nyata maupun dalam dunia maya.

5. Selalu menghargai hasil karya/upaya orang lain dan tidak langsung mencela ataupun merundung jika yang dihasilkan tidak sesuai dengan selera.

Sebagai manusia dan makhluk social sangat penting untuk menjaga etika berbicara baik itu di kehidupan nyata maupun media social (Simarmata, J. et al., 2019). Tidak semua yang dianggap baik oleh diri sendiri juga baik bagi orang lain untuk itu hendaknya lebih bijak lagi dalam memilih berbagai konten yang akan diposting di media social (Nabila et al., 2020). Keidupan pribadi hendaknya menjadi konsumsi pribadi dan hanya diri sendiri yang mengetahui, lebih selektif lagi dalam membagikan permasalahan pribadi terhadap orang lain atau teman karena tidak semua orang dapat baik dan mampu menerima apa yang terjadi dalam kehidupan. Begitupun dalam memilih teman hendaknya memilih teman yang dapat membawa dampak positif pada kehidupan, teman yang buruk akan berdampak juga pada kehidupan.

\section{KESIMPULAN}

Cyberbullying yang terjadi pada Sulli dan Goo Hara menunjukkan kurangnya pemahaman dan kesadaran masyarakat mengenai dampak cyberbullying menyebabkan kejadian yang sama berulang-ulang. Cyberbullying yang dilakukan pada umumnya mengandung fitnah dengan tujuan menjatuhkan popularitas dan reputasi Sulli dan Goo Hara.

Berdasarkan hasil penelitian yang telah dilakukan, peneliti menemukan beberapa hal yang harus dipahami oleh netizen atau masyarakat agar kejadian cyberbullying yang mengakibatkan bunuh diri ini tidak terulang kembali. Pentingnya memahami kondisi mental orang lain atau idolanya. Orang yang memiliki ganggunaan jiwa seperti depresi tidak main-main dampak buruk yang dapat ditimbulkan. Banyak pikiran-pikiran negatif yang tertanam pada alam bawah sadarnya, jangan melihat sesuatu dari satu sisi saja dan langsung menghujat karena tidak pernah tahu mengenai sesengguhnya kondisi seseorang.

Mengenai cara mencegah perilaku cyberbullying salah satunya dengan menjaga sikap serta etika dalam bermedia sosial. Santun dan sopan dalam berkomentar di Instagram. Beberapa cara untuk menjaga etika bermedia. Pertama, hindari mengomentari postingan yang mengandung SARA, kekerasan maupun pornografi banyak sekali komentarkomentar di Instagram Sulli dan Goo Hara yang berbau pornografi dan merendahkan, diperlukan penyaringan dalam berkomentar di platform media sosial karena semua orang dapat melihat komentar-komentar kita. Kedua, yang tak kalah pentingnya mencari tahu kebenaran informasi yang beredar di media massa maupun media sosial, banyak sekali informasi-informasi hoax yang beredar sehingga berakibat semakin buruknya 
depresi yang dialami oleh Sulli dan Goo Hara. Ketiga, menghargai hasil karya ataupun postingan orang lain. Ketika membagikan postingan Sulli dan Goo Hara berharap bahwa postingannya akan dapat menghibur dan menyenangkan pengikutnya, tapi yang terjadi justru sebaliknya banyak komentar-komentar negative yang diberikan, tak jarang mengandung intimidasi. Untuk itu, netizen harus lebih bijak dalam menggunakan media sosial.

\section{DAFTAR PUSTAKA}

Amini, T. Y. S. J. (2008). Bullying: Mengatasi kekerasan di sekolah dan lingkungan. Grasindo.

Andriani, N., Elita, V., Rahmalia, S., Studi, P., Keperawatan, I., \& Riau, U. (2011). Hubungan Bentuk Prilaku Bullying Dengan Tingkat Stres Pada Remaja Korban Bullying. Program Study Ilmu Keperawatan, 426-435.

Astuti, P. R. (2008). Meredam Bullying 3 Cara Efektif Meredam KPA (Kekerasan Pada Anak). Grasindo.

Barlett, C., \& Coyne, S. M. (2014). A metaanalysis of sex differences in cyberbullying behavior: The moderating role of age - Barlett - 2014 Aggressive Behavior - Wiley Online Library. Wiley. https://doi.org/https://doi.org/10.10 02/ab.21555

Bendre, N., Ebadi, N., Prevost, J. J., \& Rad, P. (2020). Human action performance using deep neuro-fuzzy recurrent attention model. Cornell University, 57749-57761. https://doi.org/10.1109/ACCESS.202 0.2982364

Breguet, T. (2007). Frequently asked questions about cyberbullying (1st ed). Rosen Pub.

Bungin, B. (2011). Sosiologi komunikasi: Teori, paradigma dan diskursus teknologi komunikasi di masyarakat. Kencana.

Elvigro, P. (2014). Secangkir kopi bully:
Memoar tentang bullying dan secuil tip inspiratif. PT Elex Media Komputindo.

Hidajat, M., Adam, A. R., Danaparamita, M., \&, \& Suhendrik, S. (2015).

Dampak Media Sosial dalam Cyber Bullying. ComTech: Computer, Mathematics and Engineering Applications, 6(1), 72. https://doi.org/https://doi.org/10.21 512/comtech.v6i1.2289

Kim, Y. E. (2019). What Yet Another KPop Star's Death Tells Us About Social Media and Mental Health.

Kowalski, R. M., Sue Limber, D., \& Agatston, P. W. (2008). Cyber bullying: bullying in the digital age. Blackwell Pub.

Levianti. (2008). Konformitas dan bullying pada siswa. Jurnal Psikologi, 6(1), 1. https://digilib.esaunggul.ac.id/konfo rmitas-dan-bullying-pada-siswa4987.html

Murphy, A. G. (2009). Dealing with bullying. Chelsea House Publications. https://www.amazon.com/DealingBullying-Character-EducationChelsea/dp/1604131217

Nabila, D., E., O., Zahira, G., Syarief, M. A. D. Y., Ryvo, A., Julianto, A. N., Abdurrachim, A., Amien, A. A., Prakoso, D. S., Affian, D., Wulandari, E. R. P., Maulana, F. V. A., Sungkono, F. P., Ardipraditiya, F. H., Putri, I. R., 
\& Andratika, J. I, W. A. (2020). Peradaban Media Sosial di Era Industri 4.o. Intrans Publishing Group.

Parsons, L. (2005). Bullied teacher, bullied student: How to recognize the bullying culture in your school and what to do about it. Pembroke Publisher.

Priyanta, A. (2010). Lets End Bullying. PT Elex Media Komputindo.

Rastati, R. (2020). ndustri K-Pop, (Cyber)bullying, dan Kesehatan Mental. Pusat Penelitian Masyarakat Dan Budaya - LIPI.

Rigby, K. (1996). Bullying in schools and what to do about it. ACER.

Rosewarne, L. (2016). Cyberbullies, cyberactivists, cyberpredators: film, $T V$, and Internet stereotypes. Santa Barbara. Praeger, an imprint of ABCCLIO, LLC.

Simarmata, J., I., Qbal, M., Hasibuan, M. S., Limbong, T., \&, \& Albra, W. (2019). Hoaks dan Media Sosial: Saring Sebelum Sharing. Yayasan Kita Menulis.

Siswati, \& Widayanti, C. G. (2011). Fenomena bullying di sekolah dasar negeri di Semarang: Sebuah studi deskriptif. Jurnal Psikologi, 5(2), 99-110.

https://ejournal.undip.ac.id/index.p hp/psikologi/article/view/35995/o

Uswatun, A. T., Wijayanti, C. P., \& Puspitasari, M. (2016). Krisis Kesantunan Berbahasa di Media Sosial Instagram Sebabkan Fenomena Cyberbullying. Saga, 6773 .

Vaillancourt, T., Faris, R., \& Mishna, F. (2017). Cyberbullying in children and youth: Implications for health and clinical practice. The Canadian Journal of Psychiatry, 62(6), 368373. https://doi.org/10.1177/0706743716 684791

Watkins, J. (2018). South Korea's Mental Health Problem-That Koreans Don't Admit. OZY.

Widiastuti, V. (2019). Kasus kekerasan terhadap audrey, psikolog ungkap 2 pemicu kekerasan. Suara.Com. https://www.suara.com/health/2019 /04/11/161033/kasus-kekerasanterhadap-audrey-psikolog-ungkap-2pemicu-kekerasan 